\title{
RECONSTRUINDO A IMAGEM/IDENTIDADE DA SELEÇÃO BRASILEIRA DE FUTEBOL: A “ERA PÓS-DUNGA” NA MÍDIA
}

\author{
Lyana Virgínia Thédiga de Miranda \\ Universidade Federal de Santa Catarina / Brasil \\ lyanathediga@gmail.com \\ Giovani De Lorenzi Pires \\ Universidade Federal de Santa Catarina / Brasil \\ giovani.pires@ufsc.br
}

\begin{abstract}
Resumo
O presente trabalho teve por objetivo identificar e analisar o discurso midiático como interlocutor social do projeto de reconstrução da imagem da seleção brasileira de futebol no período denominado Era pós-Dunga. Para tanto, apoia-se em bases teóricas sobre questões de identidade, nacionalismo e comportamento midiático, relacionando-os ao esporte (neste caso, o futebol). O corpus de pesquisa é formado por 38 matérias jornalísticas veiculadas em meios impressos, digitais e televisivos, examinados por meio da Análise de Conteúdo (AC) e de aproximações aos princípios da Análise do Discurso (AD). A pesquisa demonstrou que, ao serem institucionalizados e alavancados pela cobertura midiática, a celebração do nacionalismo, o sentimento de "brasilidade" e a autoestima afloram e materializam significados do "ser brasileiro" numa só representação: a seleção brasileira de futebol, tomada por táticas simbólicas de união e identificação da audiência pela mídia, como espelho da imagem do próprio país.
\end{abstract}

Palavras-chave: Futebol; Identidade; Discurso midiático; Copa do Mundo da FIFA.

\section{RECONSTRUCCIÓN DE LA IMAGEN/IDENTIDAD DE LA SELECCIÓN BRASILERA DE FÚTBOL: LA “ERA POS-DUNGA” EN LOS MEDIOS DE COMUNICACIÓN}

\section{Resumen}

El presente trabajo tuvo por objetivo identificar y analizar el discurso mediatico como interlocutor social del proyecto de reconstrucción de la imagen de la selección brasilera de fútbol en el período denominado Era pos-Dunga. Se apoya en bases teóricas sobre cuestiones de identidad, nacionalismo y comportamiento mediático, relacionándolos al deporte (en este caso, el fútbol) para interpretar el corpus de investigación que está formado por 38 artículos periodísticos vehiculados en medios impresos, digitales y televisivos, examinados por medio del Análisis de Contenido (AC) y de aproximaciones a los principios del Análisis del Discurso (AD). La investigación demostró que, al ser institucionalizada e impulsada por la cobertura mediática, la celebración del nacionalismo, o sentimiento de "brasilidad" y la auto-estima afloran y materializan significados del "ser brasileiro" en una sola representación: la selección brasilera de fútbol, tomada por tácticas simbólicas de unión e identificación de la audiencia por la media, como espejo de la imagen del propio país.

Palabras-clave: Fútbol; Identidad; Discurso mediático; Copa del Mundo de FIFA. 
RECONSTRUCTING THE IMAGE/IDENTITY OF THE BRAZILIAN SOCCER TEAM: THE "POST-DUNGA ERA" IN THE MEDIA

\section{Abstract}

This study aimed to identify and analyze the media discourse as a social interlocutor of the rebuilding project of the Brazilian soccer team image in the period called post-Dunga Era. It is based on theoretical questions of identity, nationalism and media behavior, relating them to the sport (in this case, football) to interpret the body of research that consists of 38 journalist articles disseminated in print, digital and television medias, examined through Content Analysis (CA) and approaches to the principles of Discourse Analysis (DA). Research has shown that, when institutionalized and leveraged by the media coverage, the celebration of nationalism, the sense of "brasilidade" and self-esteem emerge and materialize meanings of "being Brazilian" in one representation: the Brazilian national soccer team, taken by symbolic tactics of unity and identification of the audience by the media, as a mirror image of the country itself.

Key-words: Football; Identity; Media discourse; FIFA World Cup.

\section{Introdução}

Sediar grandes eventos esportivos entrou, de fato, na pauta social do país. A realização dos Jogos Pan-americanos de 2007 e a escolha do Brasil como sede da Copa do Mundo da FIFA de 2014 e dos Jogos Olímpicos e Paraolímpicos de $2016^{1}$ vem gerando a presença constante de tais eventos na agenda da grande mídia brasileira pelas mais diversas razões, entre outras, as motivações mercadológicas.

A possibilidade de lucros vislumbrada pela cobertura dos futuros megaeventos esportivos e seus desdobramentos implicam o manuseio da informação de acordo com esses interesses. Ao mercadorizar a notícia, a mídia contribui para a construção de uma cultura esportiva prescindida do todo que a originou, sendo edificada apenas em uma nesga da realidade, uma porção guarnecida de uma infinidade de interesses, entre eles ideológicos, políticos e comerciais, que ali estão camuflados.

Por considerar a realização da Copa do Mundo de 2014 como o maior evento esportivo e de mobilização social já efetivado no país, tendo em vista as proporções da competição, que envolverá doze cidades e bilhões de reais em investimentos ${ }^{2}$, e a dimensão que o futebol possui como jogo mais conhecido, praticado e discutido ${ }^{3}$ no país, pondera-se ser de grande relevância observar o

\footnotetext{
${ }^{1}$ Entre outros eventos, que fazem do período 2007- 2016, chamado "a década do esporte no Brasil".

2 Segundo informações do Portal 2014 - Arena dos negócios da Copa. Disponível em:

$<$ http://www.portal2014.org.br/noticias/5895/BNDES+PREVE+INVESTIMENTOS+DE+R+183+BILH OES+COM+COPA+E+OLIMPIADA.html>. Acesso em: $15 \mathrm{dez} .2010$

${ }^{3}$ A bibliografia sobre futebol no Brasil é bastante extensa e diversificada, sobretudo no campo das ciências sociais. Ver, entre outros: DaMatta (2006); Wisnik (2008); Franco Junior (2007); Guterman (2011).
} 
comportamento midiático esportivo em relação a tal evento, levando-se em consideração a importância da imprensa como difusora, mediadora e porta-voz de realidades ${ }^{4}$.

Além dos investimentos e da importância dirigidos à realização dos futuros megaeventos ${ }^{5}$, a cobertura esportiva durante a Copa de 2010 - mais precisamente o posicionamento midiático em relação ao técnico da seleção brasileira, o ex-jogador Dunga - desencadeou uma série de reflexões sobre a importância que os meios de comunicação delegam ao alinhamento entre o futebol e a identidade do povo brasileiro, ou seja, da representação da seleção de futebol como um espelho da imagem do próprio país.

Nessa complexa relação que envolve questões identitárias, midiatização dos eventos e comportamento editorial, a pesquisa partiu da seguinte pergunta-síntese: quais as peculiaridades do discurso midiático esportivo brasileiro empregado na reconstrução social da imagem/identidade da seleção brasileira de futebol no período aqui denominado "Era pós-Dunga"? Nosso objetivo foi investigar o discurso midiático esportivo e sua atuação como importante interlocutor social, interagindo ${ }^{6}$ na tentativa de valorização e de reestruturação da imagem da seleção brasileira de futebol, após a derrota na Copa 2010, tendo como horizonte o Mundial de 2014, que será realizado no país, sobretudo no tocante aos interesses mercadológicos envolvidos nessa (promíscua) afinidade.

Foram observadas e analisadas notícias veiculadas imediatamente após a eliminação da seleção brasileira na Copa do Mundo de 2010, realizada em julho daquele ano na África do Sul, prolongando-se pelos meses subsequentes ao final da competição ${ }^{7}$, período que denominamos como Era pós-Dunga.

Para tanto, buscou-se, por meio de acessos diários a sites, blogs e portais esportivos e jornalísticos, assim como a leitura de revistas impressas e conteúdos televisivos veiculados nos telejornais de maior expressão do país, observar e coletar matérias e entrevistas que abordassem o tema proposto e alguns elementos-chave tais como: a necessidade de renovação da seleção, a exposição do novo técnico e das "estrelas" da nova seleção, além de levantamentos sobre a Copa 2014 durante o período que perfaz a eliminação da seleção brasileira da Copa 2010 até repercussões subsequentes ao final da competição.

\footnotetext{
${ }^{4} \mathrm{O}$ presente artigo é fruto de pesquisa financiada pelo Programa Institucional de Bolsas de Iniciação Científica PIBIC/CNPq/UFSC, realizada de agosto de 2010 a julho de 2011 sob orientação do Prof. Dr. Giovani De Lorenzi Pires.

${ }^{5}$ Ver: Pires (org.), 2011.

6 A interação é entendida neste trabalho como o processo de apropriação da linguagem, por parte dos participantes da ação, pelo qual identidades e relações sociais são arquitetadas, movimento que perfaz "papel fundamental na reprodução, manutenção, ou transformação das representações que as pessoas fazem e das relações de identidades com que se definem numa sociedade". (Pinto, 2002: 28).

7 A pesquisa englobou os meses de julho/2010 a março/2011; no entanto, nas considerações finais deste texto, incluímos algumas reflexões sobre a derrota da "nova" seleção brasileira na Copa América da Argentina (2011), como um posfácio.
} 
Os procedimentos de coleta e organização dos dados foram realizados com base no referencial teórico-conceitual da Análise de Conteído (AC), conforme Bardin (2009), bem como de aproximações de práticas analíticas introdutórias da Análise de Discurso (AD) de vertente francesa (Pinto, 2002).

A escolha do recorte foi determinada não só pela factualidade da competição, cujo término enfatizou o "ponta-pé" inicial para a realização do próximo evento no Brasil, mas, sobretudo, pelo posicionamento editorial adotado pela mídia, especialmente por veículos e profissionais do sistema Globo de comunicação no período, no tocante ao técnico da seleção brasileira e seu conturbado relacionamento com os veículos de comunicação durante a competição. Partindo da hipótese de que a Confederação Brasileira de Futebol (CBF) e o sistema Globo entenderam que as atribuladas relações Dunga-mídia poderiam "contaminar" a imagem da seleção e seu valor como produto comercial e publicitário, tendo em vista a Copa de 2014, observou-se também a busca pela renovação dessa imagem da futura anfitriã de tão importante evento e, por extensão, a consolidação de uma boa imagem do próprio evento e tudo mais o que ele implica.

A relevância desse estudo situa-se na própria importância que o discurso midiático esportivo possui como disseminador de temas que envolvem paixão, símbolos e valores, caso do futebol no país. Se não muda o sentimento, e essa nem deve ser a intenção, melhora o entendimento sobre os fatos esportivos que, como não poderia deixar de ser, tornar-se-ão pauta garantida no jornalismo brasileiro dos próximos anos.

\section{Alguns apontamentos teóricos preliminares}

\subsection{Peculiaridades, modos e modelos de uma Identidade Brasileira}

Para compreendermos o significado de "ser brasileiro", partimos do entendimento apresentado por Hall (2006), de que as identidades nacionais - importantes constituintes da identidade cultural - são cultivadas por meio do atrelamento a uma cultura nacional, que lhes oferece um vasto sistema de representações, mas, nem por isso, facilmente unificadas. Para Hall (2006), elas produzem sentidos com os quais podemos ou não nos identificar e a partir deles construir nossa identidade.

Para Bitencourt (2009), as diferenças que nos compõem dificultam a formação de uma noção única, sistematizada e marcada sobre o que é ser brasileiro, diversificação essa que impossibilita a acepção de uma só identidade nacional. Mas, se por um lado, tal constatação embaraça a busca por definição, por outro não impede que lancemos mão de símbolos e valores socialmente compartilhados em uma sociedade imaginada, seja para nos diferir ou nos afirmar perante outros povos e outras culturas. 
O antropólogo Roberto Da Matta (1986) pondera que a constituição de uma identidade nacional advém do fato de compartilharmos certas características que, em contraste com o outro, formam uma referência que permite dizer quem sou eu. Para ele não importa apenas saber quem somos; o interessante é desvendarmos o mistério envolto na construção de nossas identidades, como se apresentam na instituição do ser brasileiro.

Tomemos como exemplo a comparação entre dois países: Brasil e Angola. Mesmo que o povo angolano compartilhe traços históricos conosco - a colonização portuguesa, a língua (oficial), além de pobreza estrutural, explorações infantis e constantes violações aos Direitos Humanos ${ }^{8}$-, ainda nos sentiremos diferentes dos africanos em questão. Assim, ao nos relativizarmos pela comparação, não só frente aos angolanos, mas a todos os outros povos, perceberemos uma infinidade de sistemas práticos e simbólicos que nos diferenciam, até mesmo regionalmente.

Identidade é um conceito escorregadio e está mais vinculado ao ser em contexto do que ao ser absoluto. Só há identidade na relação. É preciso um outro para que se possa estabelecer a identidade. Só há identidade na alteridade. (Bitencourt, 2009: 177).

Será partindo das peculiaridades que nos foram dadas e determinadas como comuns aos brasileiros, como por exemplo, o gosto por feijoada, carnaval, futebol, que logo perceberemos que a questão não é tão prática como pode parecer à primeira vista. O que parece ser determinante, segundo Da Matta, é a disponibilidade que cada um apresenta de ser como é, o que "indica claramente que é a sociedade que nos dá a fórmula pela qual traçamos esses perfis e com ela fazemos desenhos mais ou menos exatos" (Da Matta, 1986:13).

$\mathrm{Na}$ lista de posicionamentos, preferências e atitudes estão alguns elementos institucionalmente inseridos de tal forma que se tornaram social e naturalmente aceitáveis como características e preferências intrínsecas do ser brasileiro, definidas por um "Estado nacional e seus símbolos como um sistema que amalgama uma coletividade em torno de si" (Hobsbawn; Ranger, 1984, citados por Bitencourt, 2009: 176) por meio de "uma invenção da tradição":

significa um conjunto de práticas [...], de natureza ritual ou simbólica, que buscam inculcar certos valores e normas de comportamentos através de repetição, a qual, automaticamente, implica continuidade com um passado histórico adequado. (Hobsbawn; Ranger, 1983, citados por Hall, 2006: 54).

\footnotetext{
${ }^{8}$ Diversos autores vêm questionando a legitimidade dos Direitos Humanos perante o novo contexto cultural, social e econômico, denominado por alguns como pós-modernidade, no qual estamos inseridos atualmente, qual seja: "a globalização, o impacto das novas tecnologias, a construção de novas subjetividades e mentalidades". (Candau, 2008: 46)
} 
Tais símbolos não apenas nos reúnem como nos conferem um rótulo identitário, título esse que prontamente lançamos mão quando da necessidade de se instituir "manipulações e legitimações retóricas" (Helal; Gordon Jr., 2001: 68) acerca dos discursos de identidade nacional, situação da qual o futebol, por meio da Copa do Mundo, alça-se ao expoente máximo da coletividade em nível mundial, tendo a mídia como aglutinadora e disseminadora ativa da expressividade da identidade nacional.

Assim como degustar uma feijoada no sábado elucida uma atitude que, de forma didática, nos reúne em um arranjo coletivo, também a realização do maior evento esportivo mundial ultrapassa as (possíveis) barreiras instituídas por diferenças de classes, nesse caso, por meio de uma busca, ou mesmo a imposição, de características simbólicas que servirão como apoio ao sentimento de pertencimento e de celebração do nacionalismo.

Institucionalizado e alavancado pela cobertura midiática, adornada por táticas simbólicas de união e identificação da audiência, o sentimento de brasilidade e autoestima afloram e materializam significados do "ser brasileiro" em uma só representação: a seleção brasileira de futebol que, naquele momento, passam à condição de "190 milhões de guerreiros" 9 em campo.

2.2. Guerra, nacionalismo e futebol: a harmonia de um conjunto chamado Nação

Eu queria que a seleção fosse para a copa, como quem vai para uma batalha Eu quero jogadores que lutam no campo, como a gente luta na vida Eu quero guerreiros: porque nós também somos [coro]

E vâmo pra guerra juntos! 190 milhões de guerreiros!

Quero ver o orgulho de defender essa camisa [camisa da seleção], pra bater no peito e falar: SOU GUERREIRO, SOU HEXACAMPEÃO, SOU BRASILEIRO!

O trecho acima é parte do comercial da cerveja Brahma, primeira marca brasileira a patrocinar oficialmente uma Copa do Mundo ${ }^{10}$. O comercial destaca a expressão "guerreiros", traz imagens de guerra, com personagens trajando armaduras, mescladas a tomadas com jogos e depoimentos que tem como cenário estádios de futebol, além de uma emblemática cena na qual tudo aparece agregado: torcedores e guerreiros; lanças e bandeiras verde-amarelas, elmos e serpentinas. Um conjunto apresentado sob uma enxurrada de pedidos uníssonos de garra e obstinação, atitudes que deveriam ser incorporadas tanto pela seleção quanto pelos brasileiros, como o comercial claramente demonstra.

\footnotetext{
${ }^{9}$ Expressão usada na peça publicitária “Guerreiro na vida, guerreiros no campo", criado pela agência África para a marca de cerveja Brahma.

${ }^{10}$ Segundo o Portal da Propaganda, a oportunidade de patrocinar a Copa do Mundo de 2010 só foi possível graças a compra da Anheuser-Bush (Budweiser) pela InBev (Brahma). Após a fusão, o contrato com a FIFA foi revisado possibilitando a inclusão da marca Brahma como patrocinadora oficial da Copa do Mundo de 2010. Disponível em: <http://www.portaldapropaganda.com/comunicacao/2009/11/0028>. Acesso em: 01 mai. 2011.
} 
Ao representar o campo de futebol como arena para a batalha, vislumbram-se as demais seleções como inimigas e os nossos jogadores como guerreiros, indo além da mera representação entre a guerra enfrentada no cotidiano dos brasileiros e a vitória almejada nos campos, no caso em questão, campos africanos.

Como uma construção, um discurso ${ }^{11}$ cuja função seria criar um elo que nos reuniria em torno de uma representação do que é ser brasileiro, nesse caso durante a Copa, o comercial da cervejaria se utiliza de cinco elementos que, de acordo com Hall (2006), são os pilares estratégicos utilizados na busca pela interiorização de identidade nacional em torno de uma "comunidade imaginada" (Hall, 2006: 51): a narrativa de nação, a ênfase nas origens, a invenção da tradição, a concepção de mito e a ideia de povo original ou único.

As culturas nacionais, ao produzir sentidos sobre "a nação", sentidos com os quais podemos nos identificar, constroem identidades. Esses sentidos estão contidos nas estórias que são contadas sobre a nação, memórias que conectam seu presente com seu passado e imagens que dela são construídas. (Hall, 2006: 51)

Mas como pode ser definido um sentimento nacionalista? No texto "Guerra e Nacionalismo"12, Aldous Huxley (1977) pondera sobre o nacionalismo, o qual denomina "um dos traços mais perturbadores da nossa atual situação humana", da seguinte forma:

A guerra é condicionada por sistemas humanos e, na nossa vida moderna, o sistema simbólico é o nacionalismo. Podemos dizer que o nacionalismo é uma espécie de teologia - um sistema de conceitos, idéias e diretivas éticas - baseada numa ligação natural e instintiva ao nosso lugar de origem e a pessoas familiares, mas estendido, por meio da nossa capacidade de abstração e generalização, para bem além da natural afeição pela terra natal e pela família. O nacionalismo usa todos os recursos da educação para criar uma lealdade artificial para com áreas com as quais o indivíduo não tem muita relação e para com pessoas que jamais viu. (Huxley, 1977: 74)

Nessa rede de representações simbólicas, a seleção brasileira se institui como protagonista, um batalhão que vai à guerra lutar por seu país e defender sua bandeira e toda uma gama de produtos verde-amarelo atrelados a ações típicas do marketing esportivo de oportunidade, que pululam em tempos de Copa do Mundo. Em um evento como esse, altamente midiatizado e, por consequência, fortemente valorizado como produto, a construção do imaginário coletivo passa, em grande parte, pela

\footnotetext{
${ }^{11}$ Aqui entendido conforme a tradição da Análise de Discurso de vertente francesa que define os discursos como "práticas sociais determinadas pelo contexto sócio-histórico, mas que também são parte constitutivas daquele contexto". (Pinto, 2002: 21)

12 Apesar do livro A situação bumana ter sido publicado em 1977, o texto em questão foi uma compilação de uma aula de Huxley pronunciada em 13/04/1959, na Universidade da Califórnia, nos Estados Unidos.
} 
cobertura esportiva do evento conectada a interesses econômicos e políticos postos em jogo, seja ele dentro ou fora das quatro linhas.

\subsection{Brasil, il, il... A mídia esportiva entra em campo}

Assim como a guerra, suas táticas e artimanhas estão presentes nas regras e no vocabulário do futebol (o ataque, a defesa, artilheiro, etc.), a ideia de arquitetar uma nova imagem da seleção e dos jogadores como "guerreiros" que buscam representar a nação com afinco e seriedade não é algo recente nos noticiários esportivos que pautam tal esporte.

Ao dar destaque a uma "cobertura festiva e superficial" (Dines, 2010), que alça o sensacionalismo e o êxtase esportivo por meio de matérias que acompanham o desdobramento do nada e transformam jogadores ora em artistas, ora em bodes expiatórios, e jornalistas em "peças-chave na sustentação de um megashow patriótico, galáctico, fabulosamente lucrativo" (Dines, 2010), a transmissão de fatos de interesse público que envolvem a realização dos megaeventos esportivos pende para o entretenimento desmedido e mercadorizado, deixando de lado o que a faz ser um dos gêneros jornalísticos.

Tal panorama serviu como palco de uma saga épica, um pano-de-fundo para a investigação da apropriação midiática dos fatos esportivos no período que aqui denominamos Era pós-Dunga, mas que teve seu início como uma efusiva e conturbada Era Dunga. Nesse sentido, uma contextualização (ignorada pela mídia que, não por acaso, se apresentou imediatista e senil) se torna essencial para o bom entendimento da postura adotada pelos protagonistas dessa batalha campal, travada, principalmente, entre a Rede Globo e Dunga.

Há cerca de 20 anos (1990), a seleção brasileira buscava o tetracampeonato na Copa da Itália. No entanto, uma legião de jogadores brasileiros que atuavam no exterior, sob uma liderança frágil do técnico Sebastião Lazzaroni e muitas discussões sobre patrocínios, gratificações e direitos de imagem, sucumbiu nas quartas-de-final para a Argentina. Dunga estava entre esses jogadores e sua raça em campo, em detrimento de uma técnica mais apurada, serviu para a mídia batizar aquela seleção de forma depreciativa - injustamente, para alguns - como a Era Dunga. Era o começo de um período de críticas e mágoas entre o jogador e a mídia nacional:

Quando seu relógio marcar 13h36, hoje à tarde [quinta, 24/6/2011], Dunga completará 20 anos do momento em que correu atrás de Maradona pelo gramado do estádio Delle Alpi, em Turim. [...] O gol da derrota na Copa de 90, que consolidou a expressão "era Dunga", foi naquele 24 de junho. A expressão não nasceu ali. Foi o jornalista Cláudio Arreguy quem a cunhou, num título de matéria no Jornal do Brasil, em 1989. A ideia não era vincular a seleção de Sebastião Lazaroni ao futebol tosco, 
como aconteceu, porque Dunga não era um exemplo do jogo sem qualidade. (Coelho, 2010)

Sua chance de recuperar o prestígio e vingar-se daqueles que considera seus detratores (os jornalistas esportivos) não demorou muito. $\mathrm{Na}$ Copa de 1994, como um capitão enérgico, dentro e fora de campo ${ }^{13}$, Dunga conseguiu ir à forra com a mídia brasileira, sendo-lhe hostil e dirigindo-lhe palavras duras até mesmo no momento em que erguia a taça do sonhado tetra:

O guerreiro Dunga ouviu por quatro anos. Voltou com a faixa de capitão no braço, foi um dos líderes do time de Parreira na Copa dos EUA e, no momento de erguer a taça, desabafou com palavras impublicáveis. Seu alvo foi claro: olhou para os jornalistas brasileiros e soltou o verbo. ${ }^{14}$

Como era de se esperar, nem o título conseguiu restabelecer a paz entre Dunga e a mídia. A vitória em 1994 sempre foi contestada, por a seleção não ter apresentado um futebol bonito, que encantasse como a de 1982. O pragmatismo vitorioso de Parreira se fez representar pelo futebol vigoroso de Dunga. Uma nova Era Dunga, agora vitoriosa, porém sem obter consenso:

Difícil dizer se o ressentimento de Dunga tem mais a ver com o fato de ter virado símbolo da derrota de 90 ou com o Brasil jamais ter aceitado a vitória de 1994. Se tem a ver com a inócua discussão sobre a preferência nacional ser por vitórias como a de 1994 ou derrotas como a de 1982. (Coelho, 2010)

Após a derrota brasileira na Copa do Mundo de 2006, cujo principal diagnóstico foi a falta de amor à camisa, detectou-se a necessidade, uma demanda posta, sobretudo, pela detentora dos direitos de transmissão, a Rede Globo, e pela própria CBF: resgatar o nacionalismo perdido nas transações internacionais e no internacionalismo adquirido e refletido nos jogadores convocados. Naquele momento, era preciso assumir um compromisso com a pátria, seja por meio do repatriamento de alguns jogadores carismáticos, ação que pode significar a união do povo em torno dessa unidade nacional que é a seleção, ou pela demonstração de "pátria ou morte", digna das batalhas medievais mais sangrentas, com vistas a tornar a seleção espelho da nação que (supostamente) representa - séria, próspera, crível - e vice-versa.

Dunga, o capitão do tetra, símbolo de nacionalismo e de entrega como jogador, foi chamado para ser o treinador que recuperaria esse sentimento perdido, contribuindo para a retomada dos laços entre a seleção e a torcida brasileira, para alegria da CBF, dos patrocinadores e da detentora dos direitos de transmissão televisiva, a Rede Globo.

\footnotetext{
13 Para alguns observadores, sua melhor atuação foi controlar fora de campo o centroavante Romário, que foi o principal jogador da seleção sob a direção do técnico Carlos Alberto Parreira.

14 Disponível em < http://www.revistabrasileiros.com.br/2008/08/20/abracos-da-era-dunga/>. Acesso em 15 ago. 2010.
} 
Nos anos entre as duas Copas (2006-2010), a seleção ganhou tudo, exceto a ainda inédita medalha olímpica. Campeã da Copa América e primeira classificada nas Eliminatórias para a Copa de 2010, com vitórias expressivas sobre a rival Argentina, tudo indicava que o caminho estava correto, embora as relações entre Dunga e a mídia nunca tenham passado da tolerância mútua e à distância. Implicâncias com algumas das suas experiências com jogadores desconhecidos no Brasil e até o alegado mau-gosto do seu guarda-roupa eram motivos para a Rede Globo, sobretudo, queixar-se da distância imposta por Dunga à mídia, em treinos, viagens, etc. Mais uma etapa da Era Dunga.

A convocação final dos selecionados para a Copa da África do Sul, com a ausência de jogadores “exigidos" pela torcida (ou pela mídia?), foi o prenúncio de novos conflitos. A proibição de acesso da mídia à concentração brasileira e de entrevistas nos horários dos seus telejornais, fez com que a Globo ampliasse suas críticas e o estado permanente de beligerância com (e correspondido pelo) treinador. A derrota, mais uma vez nas quartas-de-finais, para a Holanda, foi o lance final. Antes mesmo do presidente da CBF anunciar sua demissão, a Rede Globo já cogitava quem deveria ser o treinador da seleção, agora naquela que já era a Era Pós-Dunga.

\section{Resultados e discussão}

Uma das peculiaridades do jornalismo atual são as estratégias e linguagens adotadas nos diferentes canais nos quais são veiculadas as notícias. Assim, se em um jornal os detalhes e pormenores que envolvem um fato são elevados, na televisão o tempo para a transmissão será curto e as imagens que são as privilegiadas; se nas revistas o que vale é o ponto de vista do perito no assunto, na internet imagens, minúcias e pluralidade de opiniões são o grande diferencial.

Desta forma, optou-se pela coleta em diversos veículos de mídias, oportunizando observações que pontuaram diferenças de enfoque onde se pretendia igualdade, ou mesmo repetição de conteúdos, onde se oportuniza a replicação, como é o caso da internet, meio que aglutinou a maior incidência dos dados. Neste sentido, foram acompanhadas notícias em portais de internet (UOL ,Terra e G1); em edições on line de jornais diários (Folha de São Paulo, Lance e O Globo) e revistas semanais (Veja, Isto É, Época e Carta Capital) impressas e on line. Também foram acompanhados blogs de jornalistas esportivos na UOL, ESPN Brasil e SPORTV; foram assistidos telejornais e programas esportivos da Rede Globo, emissora de televisão em sinal aberto de maior audiência no país, e por assinatura do gênero esportivo (SPORTV e ESPN Brasil), além da rádio CBN on-line.

O gráfico abaixo mostra, em números percentuais, as fontes de onde mais foram recolhidas matérias para a análise. 


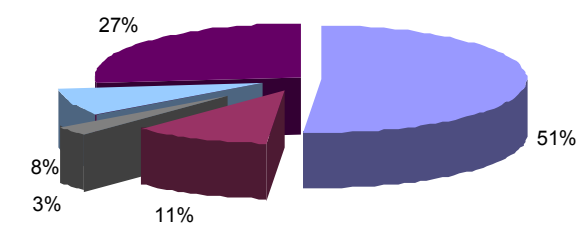

Gráfico 1: distribuição das matérias por veículo de mídia

Como já se afirmou, a coleta ocorreu no período denominado Era pós-Dunga, a partir da eliminação da seleção brasileira da Copa do Mundo e nos meses subsequentes. Assim, foram identificados alguns momentos que nortearam a observação, nos quais as notícias se reuniram em temas-chave auxiliando, de forma didática, a análise. Os momentos foram assim definidos:

a) Julho/2010: Ações de transição de cargos - da saída de Dunga até a posse de Mano Menezes, e as primeiras convocações dos jogadores;

b) Agosto/2010: Primeira atuação da "nova" seleção sob a direção do técnico Mano Menezes

c) Setembro/2010 a Março/2011: Desdobramentos da nova gestão - mandos e desmandos na CBF e Globo.

Entre as matérias coletadas logo após a eliminação do país, que demonstram uma necessidade de renovação imediata posteriormente à derrota, percebeu-se um grande apelo pela troca, não só dos componentes da seleção, mas da postura adotada durante a Era Dunga, atitude que, ao que parece, já havia sido tomada mesmo antes do final do Mundial.

Tal postura foi observada na matéria veiculada na edição do dia 03/07/2010, do Jornal Nacional, na qual o repórter Tino Marcos confirma que o jogo anterior, responsável pela eliminação da seleção na corrente Copa, tinha sido o último de Dunga como técnico. Mas, até aquele momento apenas um dia após a derrota -, nem o técnico ou os dirigentes da CBF haviam se pronunciado sobre o fato. A previsão de Tino Marcos soou como afirmação de que o percurso da seleção sob o comando de Dunga e sua política de manter os jogadores longe dos microfones, era uma questão de tempo, ou melhor, de correr atrás do tempo em que a imagem da seleção foi perdida. E retomá-la.

Assim, a mídia assumiu uma personalização ou personificação do fracasso na figura de Dunga, que naquele momento "funciona como âncora do sentido que se atribui" (Schwier, 2009: 115). Mas, 
mesmo sendo o sentido atribuído ao ex-técnico da seleção brasileira o contrário do que Schwier utilizou em sua pesquisa - o jogador Zinedine Zidane e seus atributos como incentivadores de ações publicitárias - ainda sim foi capaz de oferecer uma pluralidade de ganchos e pautas jornalísticas. Com isso,

[...] a personalização anda muito próxima do sensacionalismo que, no final das contas, implica na familiarização, simplificação, polarização, melodramatização e visualização de todos os temas (Weischenberg, 2006, citado por Schwier, 2009: 115)

Ao admitir todas as ações apresentadas por Weischenberg, a tática da personalização de Dunga como emissário simbólico do fracasso da seleção assume a função estratégica de "garantir o valor agregado de entretenimento que vai prender o espectador por mais tempo e com maior frequência ao programa" (Schwier, 2009: 115), ou, como nesse caso, a toda uma programação na qual o assunto servirá como pauta.

Para Marcondes Filho (1989), a personalização se caracteriza por ser uma ação ideológica da notícia. Nesse conjunto de representações estarão aspectos que entoam as "qualidades dos indivíduos como fatores decisivos para o rendimento esportivo do time, de vitórias e de derrotas" (Schwier, 2009: 115). Assim, quando tomada ao contrário, como é o caso do tratamento dispensado ao ex-técnico, tal atenção torna-se uma "política de perseguição personalizada" pela construção de "bodes expiatórios" (Marcondes Filho, 1989: 45).

A definição de bodes expiatórios em jornalismo e na política em geral, obedecendo à mesma lógica da personificação, funciona, num segundo momento, como método de disseminação de desconfiança, de quebra de solidariedade entre os grupos da população. [...] A técnica, portanto, tem nítidos efeitos ideológicos. (Marcondes Filho, 1989: 44)

A antecipação de Tino Marcos, que nem sequer foi uma insinuação, mas uma afirmação, aparece como uma atitude comum às notícias que, travestidas de imparcialidade, ocultam interesses além da função informativa, sendo uma "estratégia retórica comum da mídia, visando influenciar o público". (Pinto, 2002: 40)

Dois dias depois, com Dunga já fora do cargo, o presidente da CBF, Ricardo Teixeira, concede uma entrevista exclusiva ${ }^{15}$ ao programa Bem Amigos, veiculado no canal por assinatura SPORTV, um dos canais Globosat, coordenado pelo jornalista Galvão Bueno. $\mathrm{Na}$ ocasião, Teixeira justifica a permanência de Dunga até a Copa, que para os padrões da TV pareceram uma eternidade nas frias madrugadas africanas, com uma metáfora em que Dunga apareceria como um piloto de um avião em pleno vôo

15 Numa perspectiva crítica, essa entrevista exclusiva pode ser entendida como um ato de desagravo e solidariedade (ou cumplicidade) do presidente Teixeira para com as Organizações Globo. 
sobre o Atlântico, situação na qual a única coisa a se faz̧er é esperar o avião pousar para, aí sim, trocar o piloto. E, adotando uma postura comercial, acalenta o sócio e investidor, a Rede Globo personificada na figura de Bueno, anunciando que a palavra de ordem daquele momento para frente seria "renovação".

Por meio de manchetes que anunciavam que o “Time terá missão de reconquistar o torcedor" e que "Mano Menezes quer resgatar o futebol-arte na Seleção Brasileira", cerca de um mês após a eliminação o novo técnico e a concepção de uma nova seleção já era realidade. Mais uma vez, o repórter Tino Marcos realiza suas previsões, mas desta vez, bem mais otimistas.

É mais pé de ouvido do que grito. É um gaúcho com jeito um pouco mineiro de ser. Os primeiros dias de Seleção revelam um Mano Menezes imune a perguntas incômodas e inoportunas. [...]. Mano e o presidente da CBF Ricardo Teixeira reuniram os jogadores para propor um caminho: recuperar o prestígio abalado pela derrota na África do Sul e pela maneira com que a Seleção vinha sendo conduzida. É um basta à Seleção fechada, isolada. A missão é reconquistar o torcedor. [... $]^{16}$

A primeira atuação da seleção rendeu elogios e comparações. A atuação de jogadores que não foram convocados anteriormente, como Alexandre Pato, Paulo Cesar Ganso e Neymar, e a "nova postura" do técnico da seleção são ressaltadas como principais mudanças. Nesse momento, as notícias ligadas ao futebol e a seleção brasileira retoma seu viço e sua vocação para a glorificação dos "astros do gramado":

Os esportes de longa tradição - enraizada na memória coletiva - e cuja estima não se limita a certos meios ou frações da população, são especialmente apropriados para a criação de lendas, mitos ou ídolos (Schwier; Schauert, 2008, citados por Schwier, 2009: 115)

E como um arauto da renovação, Galvão Bueno, quando perguntado sobre o que achou das primeiras ações do novo técnico, respondeu de pronto:

Espetacular. Ele fez o óbvio, o que todo mundo espera do técnico da seleção: convocou os melhores. Simples, não? Eu acho que ele deveria se programar para ficar na seleção até 2016. O projeto deveria contemplar a Copa de 2014 e a Olimpíada do $\mathrm{Rio}^{17}$.

Repete-se o descrédito ao ex-técnico, em uma menção que remonta e não deixa dúvida a outras interpretações quanto à incompetência de Dunga, além do crédito declarado à nova gestão, à qual o jornalista ressalta as diferenças da anterior, dentre as quais podemos inferir que está o relacionamento com a mídia. No trecho, Galvão cita, pela primeira vez, a existência de um projeto de renovação. Nesse fragmento de discurso, a insinuação de Galvão põe em cena outros interesses, ou enunciadores,

\footnotetext{
${ }^{16}$ Bola com eles: é com os pés que se chega ao coração do torcedor - Matéria veiculada no Jornal Nacional - 10 ago. 2010. 17 A voz que vale 1 milhão. Entrevista veiculada nas Páginas Amarelas da Revista Veja - edição no 2178 - 18 ago. 2010.
} 
responsáveis pela realização de um projeto ao qual o novo técnico pertence, sendo suas atitudes estratégias pré-determinadas e vinculadas a um plano de ação maior, e que deve, como afirmou o jornalista, perdurar até 2016.

Na mesma lógica, a Revista Isto É (edição no 2127, de 18/08/2010), traz a matéria realizada pelo jornalista Amauri Segalla, intitulada "Os meninos de ouro", destacando o resgate do "jogo bonito" por meio do futebol apresentado pelos jovens craques Pato, Neymar e Ganso na seleção brasileira renovada.

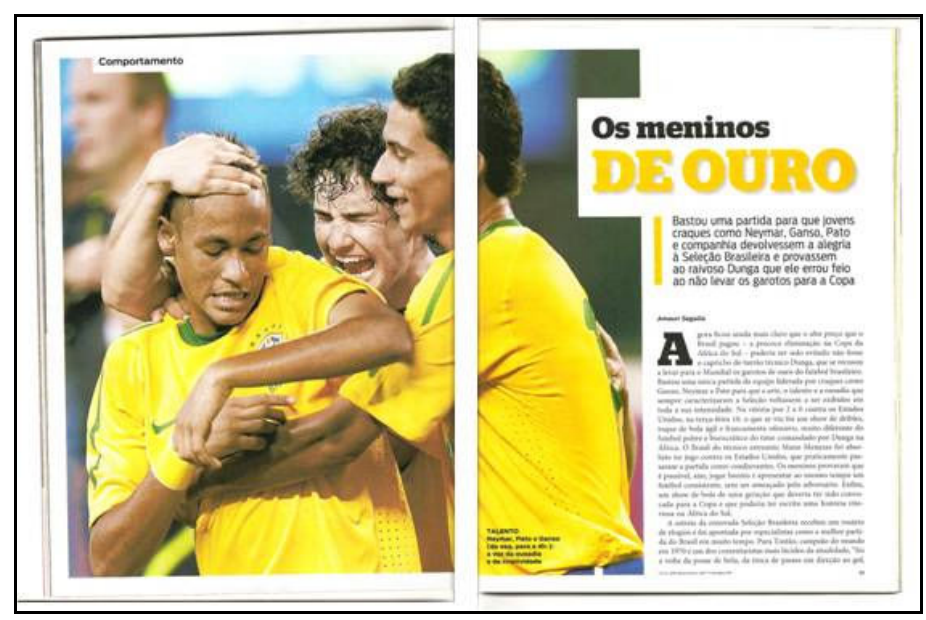

Figura 1: "Os meninos de ouro" - Revista Isto É

A comparação se concentrou nas imagens escolhidas para adornar a matéria de quatro páginas. Nas duas primeiras, uma grande foto ocupando três quartos de página com a imagem dos três jogadores citados como responsáveis pela renovação. A linha fina enfatiza:

Bastou uma partida para que os jovens craques como Neymar, Ganso, Pato e companhia devolvessem a alegria à Seleção Brasileira e provassem ao raivoso Dunga que ele errou feio ao não levar os garotos para a Copa.

Os desdobramentos que englobam as matérias da "nova" seleção mantêm, ainda, o tom de renovação e frescor de uma equipe que não possui "caras feias", conforme apontado por Galvão Bueno em matéria veiculada no dia 16/11/2010, no Jornal Nacional, por ocasião do amistoso contra a Argentina.

Assim, a nova gestão tem sua identidade formada pelo contraste com a atuação anterior, em um movimento que pretende não só exaltar os novos feitos como relembrar os "mal-feitos" antigos, como em uma lição que não deve ser esquecida, mas que não se repetirá.

Pode-se observar que mesmo com derrotas, eventos que outrora eram negativos e foram utilizados como demonstração desfavorável, não só a imagem da seleção, mas a de todo o país, na 
gestão de Mano são tomados como normais em processo de renovação, recriando o universo discursivo em torno da seleção.

\section{Considerações finais}

Em uma palestra proferida para estudantes de jornalismo, o comentarista esportivo Juca Kfouri, com toda indignação que já é clássica em suas falas, proferiu: “a imprensa brasileira é fartamente responsável pelo estado de coisas que se dão no esporte brasileiro, à medida que boa parte dela ou má parte dela é promíscua e bajula essa gente” (Kfouri, 2008: 149).

Quem já conhece o seu discurso, sabe que, por "essa gente", Kfouri indica o atrelamento da mídia esportiva às entidades do futebol, leia-se CBF e a (FIFA).

De fato, pode-se observar na pesquisa uma forte relação entre mídia, instituições que envolvem o futebol (CBF e FIFA), bem como de seus interlocutores - jornalistas, comentaristas, técnicos, jogadores, representante de instituições futebolísticas -, no estabelecimento de um novo tempo na seleção - a Era Mano? - e na busca por um só projeto: o da renovação/resgate da imagem da seleção brasileira de futebol.

A inquisição, com o técnico Dunga queimado na fogueira por seus atos extremos de nacionalismo dignos dos generais ditatoriais (ironicamente uma atitude exigida após a derrota na Copa de 2006), marcou o início de um projeto de renovação da seleção brasileira. A observação de tal acontecimento foi adotada como um eixo temático no qual foram notadas ramificações: a intenção do resgate da imagem da seleção brasileira pela CBF e sua identificação com o torcedor do país ${ }^{18}$, corroborada pelo posicionamento midiático em matérias informativas caracterizadas, por exemplo, pela adjetivação excessiva apresentada nas manchetes e pela busca incessante de um protagonismo, alçando a retomada do grupo com uma "seleção de referência" que apresenta um futebol de excelência perante o cenário mundial, sobretudo, como anfitriã da próxima Copa.

Um posfacio:

Com a realização da Copa América 2011, competição que reuniu na Argentina seleções que integram a Confederação Sul-americana de Futebol (Conmembol), tornou-se interessante não só observar o comportamento midiático adotado em relação à renovada seleção pós-Dunga, mas também, de certa forma, atualizar algumas constatações apresentadas nesse trabalho.

18 Conforme observado na entrevista do presidente da instituição, Ricardo Teixeira, ao canal SPORTV das Organizações Globo, já citada neste trabalho. 
Após a eliminação da seleção Brasileira da Copa do Mundo da África do Sul, pode-se perceber que o projeto de renovação da imagem do grupo manteve seu percurso, mas com sensíveis adequações estratégicas: a retomada da soberania, e do "valor de mercado", do futebol brasileiro com vistas ao Mundial de 2014, lançando mão do protagonismo, que inclui a presença de alguns jogadores mais maduros, como Ronaldinho Gaúcho, e a realização continuada de amistosos, em sua maioria, contra pequenas e inexpressíveis seleções, em princípio, facilmente derrotáveis. Nesse empenho, apenas o tom de culpabilidade, tal como foi investido em fatos e versões ocorridos no passado, ainda perdura, apesar das contradições.

A derrota da seleção nas quartas-de-final do torneio, quatro chances perdidas na disputa por pênaltis, por si só tornaria o assunto noticiável, afinal foi um fato histórico e uma atuação inédita. Contudo, o comportamento midiático mais uma vez mostrou-se tendencioso e contraditório.

Em uma breve observação sobre o que foi veiculado durante a competição, sobretudo centrada nos veículos da Rede Globo, mostram que em muitos casos, a gestão de Dunga ainda foi retomada como contraponto ao que se tem feito na gestão atual. E, aos que ousam questionar tal atuação, a alcunha de "bode expiatório" foi ampliada contra os que, após um ano, tentam retomar a posição de Dunga em 2010, denominados como "viúvas de Dunga"19:

- Tô com o Mano nessa questão de 2014, acho que o Brasil tem tudo para chegar com uma boa seleção. Vamos dar tempo para Neymar e Ganso, tirar o Neymar e o Ganso dessa discussão.

- Continuo achando que o Neymar e o Ganso deveriam ter ido para a Copa do mundo de 2010, em resposta a viúvas do Dunga que se manifestam "Ah, o Dunga estava certo em não levar o Neymar e o Ganso". Até porque, se tivessem ido à Copa do Mundo, provavelmente estariam melhor hoje, mais maduros.

Incessante na tarefa, mídia e CBF continuam lançando mão de estratégias de personalização, tanto dos fracassos quanto dos sucessos, em um culto perpétuo entre mal e bem: Dunga como "bode expiatório" e "os meninos de ouro", que nesse caso compartilham a condição de protagonistas, em indivíduos nos quais devemos depositar esperança e confiança.

Como duas faces de uma mesma moeda, subjaz nas notícias sobre a seleção o "produto de atitudes e comportamentos de pessoas, isoladamente (...) que se impõem contra tudo e contra todos para afirmar o seu poderio diante dos homens comuns" (Marcondes Filho, 1989: 43), como incansavelmente é julgado o ex-técnico brasileiro, juntamente com "popstars", usando, entre outros, extravagância, a imagem, o look como instrumento de publicidade" de jogadores e esportistas que "por acaso, também jogam futebol” (Schwier, 2009: 116).

${ }^{19}$ Debate entre comentaristas do SPORTV na Mesa Redonda especial sobre a Copa América - 19 jul. 2011, grifo nosso. 


\section{Referências}

BARDIN, Laurence (2009). Análise de conteúdo, 2 ed. Lisboa: Edições 70.

BITENCOURT, Fernando G. (2009) Esboço sobre algumas implicações do futebol e da copa do mundo para o Brasil: identidade e ritos de autoridade. Revista Brasileira de Ciências do Esporte, Campinas, v. 30, n. 3, p. 173-189.

CANDAU, Vera (2008). Direitos humanos, educação e interculturalidade: as tensões entre igualdade e diferença. Revista Brasileira de Educação, v. 13, n. 37.

COELHO, Paulo Vinicius (2010). Não era Dunga. Observatório da Imprensa, ano $15-\mathrm{n}^{\circ} 595$. Disponível em: < http://www.observatoriodaimprensa.com.br/news/view/nao-era-dunga $>$. Acesso em: 10 nov.2011.

COPA DO MUNDO DE FUTEBOL. Bem amigos, Rio de Janeiro: SPORTV, 05 jul. 2010. Programa de televisão.

COPA AMÉRICA DE FUTEBOL. Mesa redonda, Rio de Janeiro: SPORTV, 19 jul. 2011. Programa de televisão.

DAMATTA, Roberto (1986). O que faz o Brasil, Brasil? Rio de Janeiro: Rocco.

(2006). A bola corre mais que os homens: duas copas, treze crônicas e três ensaios sobre

futebol. Rio de Janeiro: Rocco.

DINES, Alberto (2010). Imprensa na copa: cobertura festiva, superficial. Observatório da Imprensa, ano 16, n. 597. Disponível em:

<http://www.observatoriodaimprensa.com.br/artigos.asp?cod=597JDB001>. Acesso em 10 set. 2010.

FRANCO JUNIOR, Hilário (2007). A dança dos deuses: futebol, sociedade e cultura. São Paulo: Companhia das Letras.

FUTEBOL. Jornal Nacional, Rio de Janeiro: Rede Globo, 10 ago. 2010. Programa de televisão.

GUTERMAN, Marcos (2011). O futebol explica o Brasil: uma história da maior expressão popular do país. São Paulo: Contexto.

HALL, Stuart (2006). A identidade cultural na pós-modernidade. Rio de Janeiro: DP\&A.

HELAL, Ronaldo; GORDON JR., César (2001). Sociologia, história e romance na construção da identidade nacional através do futebol. In: HELAL, Ronaldo. A invenção do país do futebol: mídia, raça e idolatria. Rio de Janeiro: Mauad.

HUXLEY, Aldous (1977). A situação humana. São Paulo: Círculo do Livro. 
KFOURI, Juca (2008). Nosso futebol é a cara do Brasil. O Brasil em Debate na Assembléia Legislativa, Florianópolis. v. 2, p. 133-155.

MARCONDES FILHO, Ciro (1989). O capital da notícia. São Paulo: Ática.

PINTO, Milton José (2002). Comunicação e discurso: introdução à análise de discursos. São Paulo: Hacker Editores.

PORTELA, Fábio (2010). A voz que vale 1 milhão. Revista Veja. Edição no 2178 - p. 19; 22-23. 18 ago. 2010

PIRES, Giovani De Lorenzi (org.) et al. (2011). O Brasil na Copa, a Copa no Brasil. Florianópolis: Tribo da Ilha.

SCHWIER, Jürgen (2009). A midiatização do esporte. in Malina, André; Cesário, Sebastiana (org.). Esporte: fator de integração e inclusão social? Campo Grande: Editora UFMS, p. 105-118

WISNIK, José Miguel (2008). Veneno remédio: o futebol e o Brasil. São Paulo: Companhia das Letras. 